\title{
Editorial
}

\section{The long and short of it: long noncoding RNAs in neural development and diseases}

\author{
Jinwei Zhang ${ }^{1, *}$ \\ ${ }^{1}$ Laboratory of Molecular Biology, National Institute of Diabetes and Digestive and Kidney Diseases, Bethesda, MD \\ 20892, USA
}

\section{TABLE OF CONTENTS}

1. Versatile and stratified functionalities of IncRNAs

2. Regulatory roles of IncRNAs in neural development and pathology

3. Acknowledgment

4. Funding

5. Conflict of interest

6. References

\section{Versatile and stratified functionalities of IncRNAs}

Long noncoding RNAs (lncRNAs) are emerging nucleic acid polymers that play key regulatory and structural roles in numerous cellular processes [1-3]. While the true gamut of their impressive functional repertoire still awaits full investigation, much is now known about some of their diverse nuclear and cytoplasmic functions. In the nucleus, lncRNAs can reshape chromosome architecture, modulate chromatin interactions and remodeling, regulate transcription initiation and elongation, etc. [4-10]. Notably, both the act of lncRNA biogenesis and the resulting transcripts can contribute to regulation [11, 12]. Interestingly, lncRNAs are also found to act as scaffolds to nucleate the formation of dynamic ribonucleoprotein assemblies termed nuclear bodies [13-15]. Although most IncRNAs are retained in the nucleus, some function in the cytoplasm and even mitochondria to rheostat mRNA stability and translation, through direct interactions with $\mathrm{mR}$ NAs, microRNAs, RNA-binding proteins, and even ribosomes [16-18]. Even post-translational modification such as phosphorylation can be controlled by lncRNAs by altering target protein interaction with kinases and phosphatases [19, 20].

Despite these fascinating biological effects, there exist significant barriers in the functional and mechanistic elucidations of lncRNAs. First, frequent gene redundancy in humans makes it difficult to assign function to individual lncRNA genes based on single-gene manipulations. This is exemplified by the case of Drosophila roX1 and roX2 genes and possibly also MALAT-1 (Metastasis Associated Lung Adenocarcinoma Transcript 1) genes [21-
23]. Second, as lncRNA genes can function at various points of regulation and in distinct forms, it can be difficult to distinguish among the effects of the lncRNA transcripts per se, protein products some lncRNAs are now known to encode, and the act of their transcription and processing $[10,24]$. Third, the primary sequences of most lncRNAs are not well conserved, and many of them are limited to mammalian genomes [25, 26]. This hampers effective multiple sequence alignments which are used to extract information about conserved regions and sequence motifs. Finally, at the levels of secondary and tertiary structures, many if not most lncRNAs exhibit limited sequence covariation that would support the presence of well-conserved stem regions, which are hallmarks of conserved functional structures found in known structured RNAs [25, 27, 28]. With the recent flourish and application of artificial intelligence and neural networks in biology, there may be opportunities to apply these emerging technologies in the analysis, classification, pattern search, and prediction of the secondary and tertiary structures of lncRNAs. If successful, these approaches may also provide another route towards establishing structure-function relationships.

\section{Regulatory roles of IncRNAs in neural development and pathology}

The versatile and stratified functionalities of lncRNAs are especially pronounced in the central nervous system (CNS), particularly in the brain. Many lncRNAs are expressed to much higher levels in the brain and some conserved lncRNAs appear to be brain-specific [29, 30]. These findings are in line with the notion that gene expression programs during CNS and brain development, compare to 
A

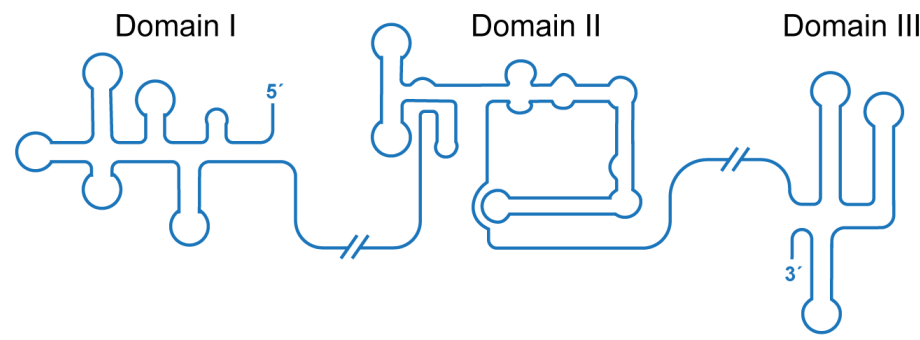

B
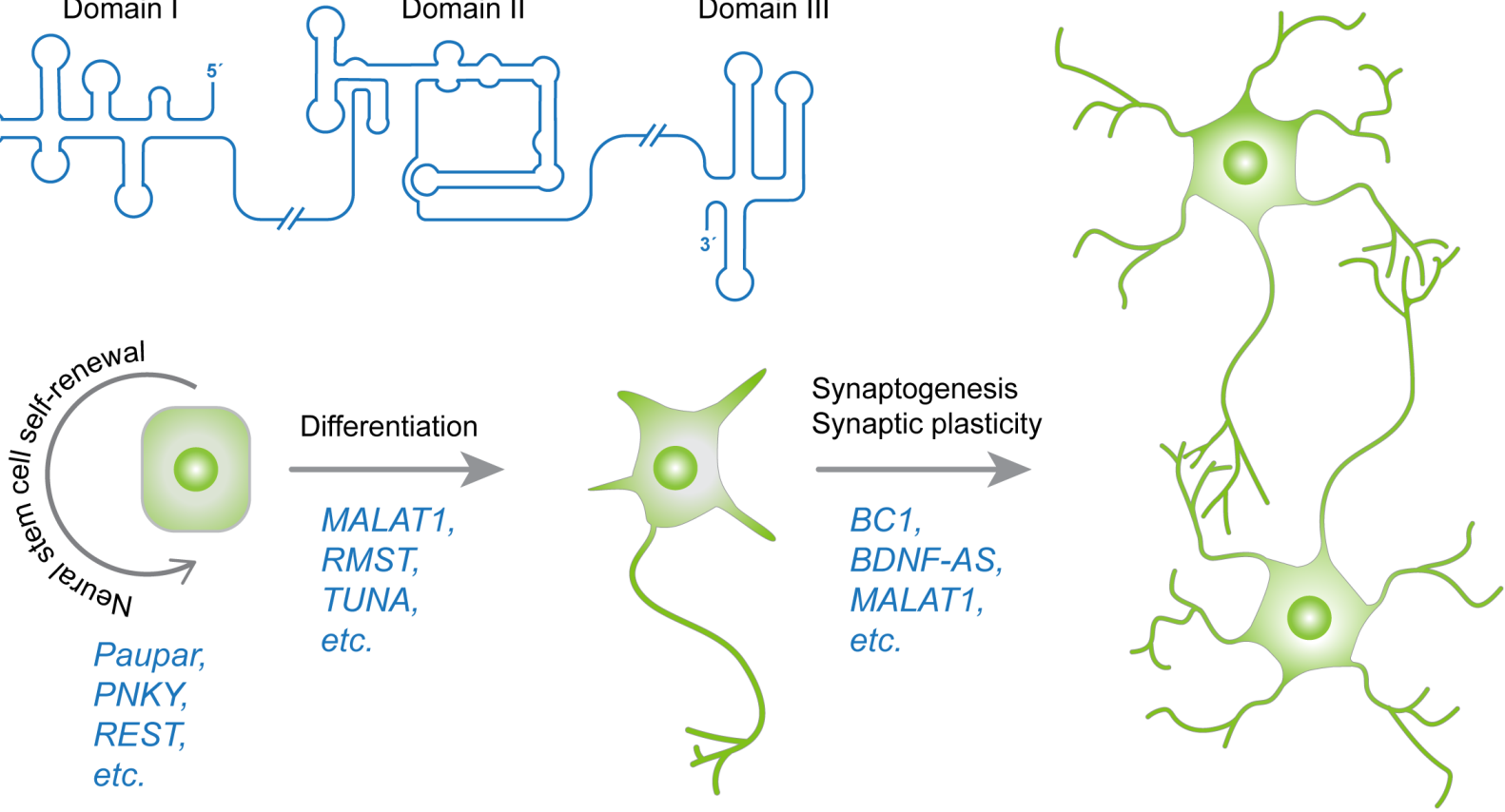

Fig. 1. A simplified view of regulatory IncRNA functions in neural development and pathology. (A) Multi-domain secondary structure of an envisioned lncRNA, featuring numerous hairpin stem loops, single-stranded regions, multi-helix junctions, compact domains harboring tertiary folds, long-range interactions such as pseudoknots, etc. (B) Diagram of neural development regulation by representative lncRNAs. Depicted are lncRNAregulated developmental phases of neural stem cell self-renewal (left), commitment to differentiation (middle), and synaptogenesis and synaptic plasticity (right).

those of other tissues and organs, require more precise, sophisticated and coordinated control. However, as discussed above, the mechanistic analyses of lncRNAs in various biological contexts have been challenging, due to their low copy numbers, gene redundancy, general lack of significant sequence conservation and co-variation, and a paucity of structural information at secondary, tertiary and quaternary levels (Fig. 1A) [27, 31-33]. Indeed, high-resolution structural and mechanistic analyses of noncoding RNAs much smaller than most lncRNAs are already technically challenging, despite the recent resolution revolution brought by single-particle cryo-EM analyses [34-38]. These deficiencies have partially contributed to seemingly conflicting findings and models for the proposed mechanisms of action by some lncRNAs. Therefore, comparative meta-analyses that compare and contrast multiple lines of evidence to synthesize and derive general insights and trends are valuable, at this early developmental stage of lncRNA biology.

One such analysis, by Oe et al. [39], starts with the known roles of select lncRNAs in the course of neuronal differentiation, from the self-renewal of the neuronal stem cells, to commitment to cell fates, and to their functional maturation (Fig. 1B). Indeed, a great number of lncRNAs contribute to this initial phase of neural development, including MALAT1, TUNA (Tcl1 Upstream NeuronAssociated lincRNA), etc. [40, 41]. Once the neurons have differentiated and their characters assigned, dendrites and axons grow outward and make the first synapses to start forming neural circuits, in a process known as synaptogenesis. LncRNAs such as MALAT1, FMR4 (fragile X mental retardation 4) and BC1 (Brain cytoplasmic RNA 1) regulate synaptogenesis or synaptic plasticity [40,42]. Synaptic plasticity is the final phase of neural development in which synaptic transmissions change strength or efficacy in response to stimuli, and is essential for brain functions including learning and memory. Interestingly, synaptic plasticity is suggested to also modulate the expression of a large set of lncRNAs, thus allowing for mutual regulation and potential feedback control [43].

Logically, deregulation of IncRNA expression and operation is linked to the onset and pathogenesis of a number of neurological diseases. Oe et al. [39], focuses on discussing known correlations between lncRNA deregulation and primary neurological diseases including neurodegenerative diseases such as Alzheimer's and Parkinson's diseases, and glioma, brain cancers of glial cells that surround and support neurons. Interestingly, the proposed mechanistic pathways connecting the implicated lncRNAs (e.g., HOTAIR, NEAT1, 51A) to the disease pathologies frequently involved direct lncRNA interactions with microRNAs, regulation of target mRNA and protein stability, as well as epigenetic regulation such as alteration of DNA methylation.

While the analysis of Oe et al. [39], highlights two decades of exciting progress at the crossroads between lncRNA biology and neural development and pathology, much remains to be affirmed and clarified, in order to trans- 
late such basic knowledge to reliable diagnostics, therapies and clinical applications. What is also clear is that fundamental mechanistic analyses of lncRNAs at the molecular and structural level are needed to deepen our understanding of these newly adopted regulatory polymers, which frequently exhibit novel and often surprising modes of operation and unusual patterns of conservation [32, 44].

\section{Acknowledgment}

The author thanks previous and current members of the laboratory for their valuable contributions and insightful discussions.

\section{Funding}

This work was supported by the Intramural Research Program of the NIH, The National Institute of Diabetes and Digestive and Kidney Diseases (NIDDK), ZIADK075136 to JZ, and a NIH Deputy Director for Intramural Research (DDIR) Challenge Award.

\section{Conflict of interest}

The author declares no conflict of interest.

\section{References}

[1] Cech T, Steitz J. The Noncoding RNA Revolution-Trashing Old Rules to Forge New Ones. Cell. 2014; 157: 77-94.

[2] Statello L, Guo C, Chen L, Huarte M. Gene regulation by long non-coding RNAs and its biological functions. Nature Reviews Molecular Cell Biology. 2021; 22: 96-118.

[3] Yao R, Wang Y, Chen L. Cellular functions of long noncoding RNAs. Nature Cell Biology. 2019; 21: 542-551.

[4] Chen CK, Blanco M, Jackson C, Aznauryan E, Ollikainen N, Surka $\mathrm{C}$, et al. Xist recruits the $\mathrm{X}$ chromosome to the nuclear lamina to enable chromosome-wide silencing. Science. 2016; 354: 468-472.

[5] Rinn JL, Kertesz M, Wang JK, Squazzo SL, Xu X, Brugmann $\mathrm{SA}$, et al. Functional Demarcation of Active and Silent Chromatin Domains in Human HOX Loci by Noncoding RNAs. Cell. 2007; 129: 1311-1323.

[6] Zhao J, Sun BK, Erwin JA, Song J-, Lee JT. Polycomb Proteins Targeted by a Short Repeat RNA to the Mouse X Chromosome. Science. 2008; 322: 750-756.

[7] Calo E, Flynn RA, Martin L, Spitale RC, Chang HY, Wysocka J. RNA helicase DDX21 coordinates transcription and ribosomal RNA processing. Nature. 2015; 518: 249-253.

[8] Mariner PD, Walters RD, Espinoza CA, Drullinger LF, Wagner $\mathrm{SD}$, Kugel JF, et al. Human Alu RNA is a modular transacting repressor of mRNA transcription during heat shock. Molecular Cell. 2008; 29: 499-509.

[9] Xing Y, Yao R, Zhang Y, Guo C, Jiang S, Xu G, et al. SLERT Regulates DDX21 Rings Associated with Pol i Transcription. Cell. 2017; 169: 664-678.e16.

[10] Wu M, Xu G, Han C, Luan P, Xing Y, Nan F, et al. LncRNA SLERT controls phase separation of FC/DFCs to facilitate Pol I transcription. Science. 2021; 373: 547-555.

[11] Engreitz JM, Haines JE, Perez EM, Munson G, Chen J, Kane M, et al. Local regulation of gene expression by lncRNA promoters, transcription and splicing. Nature. 2016; 539: 452-455.

[12] Latos PA, Pauler FM, Koerner MV, Şenergin HB, Hudson QJ, Stocsits RR, et al. Airn transcriptional overlap, but not its lncRNA products, induces imprinted Igf2r silencing. Science. 2012; 338: 1469-1472.

[13] Clemson CM, Hutchinson JN, Sara SA, Ensminger AW, Fox AH, Chess A, et al. An Architectural Role for a Nuclear Noncoding RNA: NEAT1 RNA is Essential for the Structure of Paraspeckles. Molecular Cell. 2009; 33: 717-726.

[14] Yin Q, Yang L, Zhang Y, Xiang J, Wu Y, Carmichael GG, et al. Long noncoding RNAs with snoRNA ends. Molecular Cell. 2012; 48: 219-230.

[15] Wilusz JE, Freier SM, Spector DL. 3' end processing of a long nuclear-retained noncoding RNA yields a tRNA-like cytoplasmic RNA. Cell. 2008; 135: 919-932.

[16] Gong C, Maquat LE. LncRNAs transactivate STAU1-mediated mRNA decay by duplexing with 3' UTRs via Alu elements. Nature. 2011; 470: 284-288.

[17] Carrieri C, Cimatti L, Biagioli M, Beugnet A, Zucchelli S, Fedele S, et al. Long non-coding antisense RNA controls Uchl1 translation through an embedded SINEB2 repeat. Nature. 2012; 491: 454-457.

[18] Lee S, Kopp F, Chang T, Sataluri A, Chen B, Sivakumar S, et al. Noncoding RNA NORAD Regulates Genomic Stability by Sequestering PUMILIO Proteins. Cell. 2016; 164: 69-80.

[19] Wang P, Xue Y, Han Y, Lin L, Wu C, Xu S, et al. The STAT3binding long noncoding RNA lnc-DC controls human dendritic cell differentiation. Science. 2014; 344: 310-313.

[20] Liu B, Sun L, Liu Q, Gong C, Yao Y, Lv X, et al. A cytoplasmic NF-kB interacting long noncoding RNA blocks IкB phosphorylation and suppresses breast cancer metastasis. Cancer Cell. 2015; 27: 370-381.

[21] Meller VH, Rattner BP. The roX genes encode redundant malespecific lethal transcripts required for targeting of the MSL complex. EMBO Journal. 2002; 21: 1084-1091.

[22] Kim J, Piao H, Kim B, Yao F, Han Z, Wang Y, et al. Long noncoding RNA MALAT1 suppresses breast cancer metastasis. Nature Genetics. 2018; 50: 1705-1715.

[23] Arun G, Diermeier S, Akerman M, Chang K, Wilkinson JE, Hearn S, et al. Differentiation of mammary tumors and reduction in metastasis upon Malat1 lncRNA loss. Genes \& Development. 2016; 30: 34-51.

[24] Matsumoto A, Pasut A, Matsumoto M, Yamashita R, Fung J, Monteleone E, et al. MTORC1 and muscle regeneration are regulated by the LINC00961-encoded SPAR polypeptide. Nature. 2017; 541: 228-232.

[25] Johnsson P, Lipovich L, Grandér D, Morris KV. Evolutionary conservation of long non-coding RNAs; sequence, structure, function. Biochimica et Biophysica Acta. 2014; 1840: 10631071.

[26] Ruan X, Li P, Chen Y, Shi Y, Pirooznia M, Seifuddin F, et al. In vivo functional analysis of non-conserved human IncRNAs associated with cardiometabolic traits. Nature Communications. 2020; 11: 45.

[27] Rivas E, Clements J, Eddy SR. A statistical test for conserved RNA structure shows lack of evidence for structure in lncRNAs. Nature Methods. 2017; 14: 45-48.

[28] Diederichs S. The four dimensions of noncoding RNA conservation. Trends in Genetics. 2014; 30: 121-123.

[29] Derrien T, Johnson R, Bussotti G, Tanzer A, Djebali S, Tilgner $\mathrm{H}$, et al. The GENCODE v7 catalog of human long noncoding RNAs: analysis of their gene structure, evolution, and expression. Genome Research. 2012; 22: 1775-1789.

[30] Ponjavic J, Oliver PL, Lunter G, Ponting CP. Genomic and transcriptional co-localization of protein-coding and long noncoding RNA pairs in the developing brain. PLoS Genetics. 2009; 5: e1000617. 
[31] Guo CJ, Ma XK, Xing YH, Zheng CC, Xu YF, Shan L, et al. Distinct Processing of IncRNAs Contributes to Non-conserved Functions in Stem Cells. Cell. 2020; 181: 621-636.e22.

[32] Palazzo AF, Koonin EV. Functional Long Non-coding RNAs Evolve from Junk Transcripts. Cell. 2020; 183: 1151-1161.

[33] Brown JA, Valenstein ML, Yario TA, Tycowski KT, Steitz JA. Formation of triple-helical structures by the 3'-end sequences of MALAT1 and MEN $\beta$ noncoding RNAs. Proceedings of the National Academy of Sciences of the United States of America. 2012; 109: 19202-19207.

[34] Hood IV, Gordon JM, Bou-Nader C, Henderson FE, Bahmanjah S, Zhang J. Crystal structure of an adenovirus virus-associated RNA. Nature Communications. 2019; 10: 2871.

[35] Li S, Su Z, Lehmann J, Stamatopoulou V, Giarimoglou N, Henderson $\mathrm{FE}$, et al. Structural basis of amino acid surveillance by higher-order tRNA-mRNA interactions. Nature Structural \& Molecular Biology. 2019; 26: 1094-1105.

[36] Suddala KC, Zhang J. High-affinity recognition of specific tRNAs by an mRNA anticodon-binding groove. Nature Structural \& Molecular Biology. 2019; 26: 1114-1122.

[37] Uroda T, Chillón I, Annibale P, Teulon J, Pessey O, Karuppasamy M, et al. Visualizing the functional 3D shape and topography of long noncoding RNAs by single-particle atomic force microscopy and in-solution hydrodynamic techniques. Nature Protocols. 2020; 15: 2107-2139.

[38] Qu G, Kaushal PS, Wang J, Shigematsu H, Piazza CL, Agrawal $\mathrm{RK}$, et al. Structure of a group II intron in complex with its reverse transcriptase. Nature Structural \& Molecular Biology. 2016; 23: 549-557.
[39] Oe S, Kimura T, Yamada H. Regulatory non-coding RNAs in nervous system development and disease. Frontiers in Bioscience. 2019; 24: 1203-1240.

[40] Bernard D, Prasanth KV, Tripathi V, Colasse S, Nakamura T, Xuan $\mathrm{Z}$, et al. A long nuclear-retained non-coding RNA regulates synaptogenesis by modulating gene expression. EMBO Journal. 2010; 29: 3082-3093.

[41] Lin N, Chang K, Li Z, Gates K, Rana ZA, Dang J, et al. An evolutionarily conserved long noncoding RNA TUNA controls pluripotency and neural lineage commitment. Molecular Cell. 2014; 53: 1005-1019.

[42] Muslimov IA, Santi E, Homel P, Perini S, Higgins D, Tiedge H. RNA transport in dendrites: a cis-acting targeting element is contained within neuronal BC1 RNA. Journal of Neuroscience. 1997; 17: 4722-4733.

[43] Maag JLV, Panja D, Sporild I, Patil S, Kaczorowski DC, Bramham CR, et al. Dynamic expression of long noncoding RNAs and repeat elements in synaptic plasticity. Frontiers in Neuroscience. 2015; 9: 351.

[44] Baker M. Long noncoding RNAs: the search for function. Nature Methods. 2011; 8: 379-383.

Send correspondence to: Jinwei Zhang, Laboratory of Molecular Biology, National Institute of Diabetes and Digestive and Kidney Diseases, Bethesda, MD 20892, USA, E-mail: jinwei.zhang@nih.gov 